LBL-34612

UC-410

\title{
New Vision on Surface Diffusion
}

\author{
Xu-Dong Xiao, Yuanlin Xie, and Y.R. Shen \\ Department of Physics \\ University of California \\ and \\ Materials Sciences Division \\ Lawrence Berkeley Laboratory \\ University of California \\ Berkeley, California 94720
}

August 1993

This work was supported by the Director, Office of Energy Research, Office of Basic Energy Sciences, Materials Sciences Division, of the U.S. Department of Energy under Contract No. DE-AC03-76SF00098.

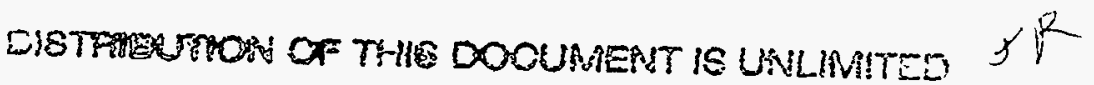




\section{DISCLAIMER}

This report was prepared as an account of work sponsored by an agency of the United States Government. Neither the United States Government nor any agency thereof, nor any of their employees, make any warranty, express or implied, or assumes any legal liability or responsibility for the accuracy, completeness, or usefulness of any information, apparatus, product, or process disclosed, or represents that its use would not infringe privately owned rights. Reference herein to any specific commercial product, process, or service by trade name, trademark, manufacturer, or otherwise does not necessarily constitute or imply its endorsement, recommendation, or favoring by the United States Government or any agency thereof. The views and opinions of authors expressed herein do not necessarily state or reflect those of the United States Government or any agency thereof. 


\section{DISCLAIMER}

Portions of this document may be illegible in electronic image products. Images are produced from the best available original document. 
LBL -34612

UC 410

\title{
New Vision on Surface Diffusion
}

\author{
Xu-Dong Xiao, Yuanlin Xie, and Y. R. Shen \\ Department of Physies, University of California \\ Materials Sciences Division, Lawrence Berkeley Laboratory \\ Berkeley, California 94720
}

\begin{abstract}
Atthough surface diffusion has been a subject of extensive studies, its understanding is still rudimentary. ${ }^{1}$ Experimental results are limited because of lack of widely applicable techniques. We have recently developed a novel technique ultilizing optical diffraction from a laser-induced ono-dimensional monolayer grating to probe chemical surface diffusion. ${ }^{2,3}$ Since the diffusion
\end{abstract} involved is one-dimensional, it can be easily analyzed. By varying the grating period, the measurable diffusion coefficient can have a dynamic range of about 8 orders of magnitude, from $10^{-6} \mathrm{~cm}^{2} / \mathrm{sec}$ to $10^{-15} \mathrm{~cm}^{2} / \mathrm{sec}$. If the grating is property oriented, anisotropic surface diffusion can be readily measured. Aso the tectnique is applicable to both metals and semiconductors and probabty even insulators or fluids. Finally, with linear optical diffraction, the sensitivity of the technique can be so high that a grating with a modulation of a few percent of a monolayer is easily detectable. ${ }^{3}$ Therefore, the coverage dependence of surface diffusion can also be investigated. We have used this technique to study $\mathrm{CO}$ diffusion on $\mathrm{Ni}(110)$. We are interested in: i) the coverage dependence of anisotropic diffusion; ii) impurities effects on diffusion; and iii) defect effects on diffusion.

The experiment was performed in an ultrahigh vacuum (UHV) chamber with a base pressure of $2.0 \times 10^{-10}$ torr. The Ni(110) sample was cut and potished to within $0.2^{\circ}$ from the $(110)$ plane. The sample surface was prepared in the usual way. ${ }^{2}$ Auger spectra showed no detectable surface impurities $(<0.3 \%$ for $S$ and $C$, and $<3 \%$ for $O$ ) after the cleaning procedure. A sharp $\{x \mid$ LEED pattem from the bare $N i(110)$ surface and a clear $2 \times 1$ LEED pattem from a full CO monolayer on the surface could be observed.

To create a CO grating on $\mathrm{Ni}(110)$, laser-induced thermal cesorption with two interfering pulsed laser beams from a single-mode Q-switcheo Nd:YAG laser was used. The depth of the adsorbate grating was controlled by properly adjusting the beam intensities. ${ }^{2}$ We chose to have in our experiment a graung period of $-3 \mu \mathrm{m}$ and a coverage modulation of $-0.03 \mathrm{ML}$ on an adjustable

average coverage $\bar{\theta}$. With such a small coverage modulation, the diffusion coefficient measured can be well approximated by a constant depending only on the average coverage. Linear optical diffraction could be used to probe the grating. In our experiment a signal-to-noise ratio of 10 was obtained. 
Surface diffusion leads to smearing of the monolayer grating. As a result, the first-order optical diffraction signal decays as ${ }^{3}$

$$
S(t)=S_{0} \exp \left(-8 \pi^{2} D t / s^{2}\right) \text {. }
$$

where the decay constant is proporticinal to the diffusion coefficient $D$ and inversely proportional to the square of the grating period s. Knowing $S$, we can deduce $D$ from a fit of Eq.(1) to the measured $S(t)$. Some typical results are shown in Fig. 1. From such data, D versus temperature $T$ could be obtained and fit by the Arthenius law

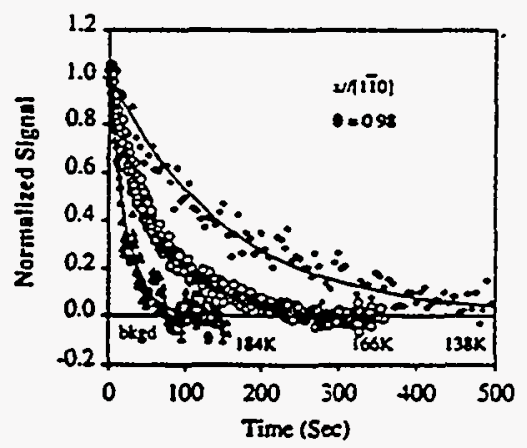

$$
D=D_{0} \exp \left(\cdot \frac{E_{\text {diff }}}{k_{B} T}\right)
$$

Figure 1: Linear diffraction signals versus time for coverage $\theta=0.98 \mathrm{ML}$ at three temperatures

for diffusion along [1 $\overline{10}$ ]. The solid lines are single exponential fils by Eq. (1).

The preexponential factor $D_{0}$ and the diffusion activation energy $E_{\text {dff }}$ could then be found.
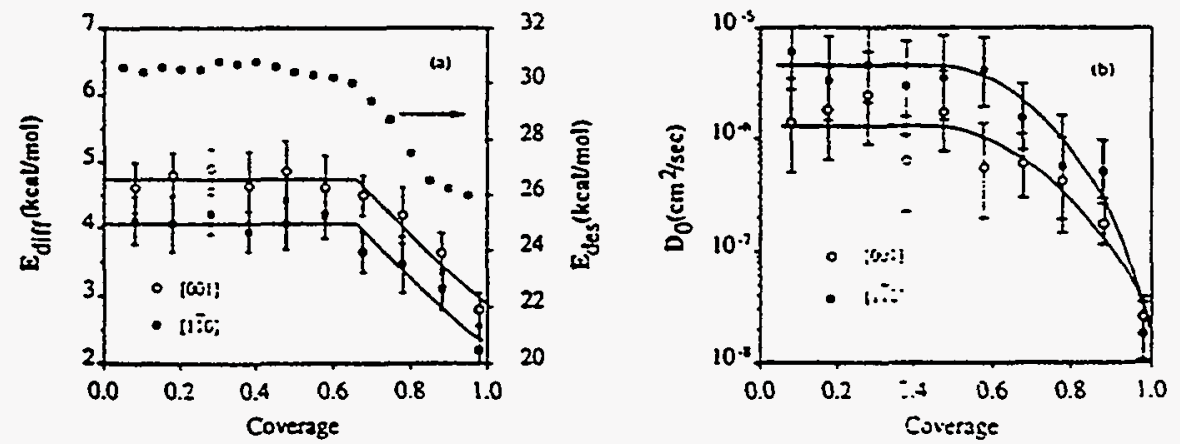

Figure 2: (a) Diffusion activation energy and (b) preexponential tactor as a function of CO

coverage $\theta$ for CO diffusion along [1 10] and [001]. The solid lines in (a) are theoretical fits using a simple lattice gas model with masn fietd approximation, but the solid lines in (b) are only for eyeguide. The desorption energy as a function of coverage $\theta$ from Ret. 11 is reproduced in (a) for comparison. 
For measurements of anisotropic surface diffusion, the $\mathrm{CO}$ monolayer grating could be oriented on $\mathrm{Ni}(110)$ along various directions. The average $\mathrm{CO}$

coverage $\bar{\theta}$ was also varied for studies of coverage dependence in the diffusion. Figure 2 shows how our experimentally determined $E_{\text {dif }}$ and $D_{0}$ for $C O$ diffusion

on $\mathrm{Ni}(110)$ along [1 $1 \overline{1} 0$ ] and [001] vary with the average CO coverage $\bar{\theta}$. In both directions, $E_{\text {ditt }}$ is essentially constant up to a CO coverage of $0.7 \mathrm{ML}$ and then decreases monotonically towards full coverage, with $D_{0}$ behaving the same way.

The CO-CO imeraction is clearly important for surtace diffusion with $\bar{\theta}$ higher than $0.7 \mathrm{ML}$, but does not seem to have contributed additional anisotropy to $E_{\text {ditt }}$

since the difference in $E_{d i t f}$ along [1 $1 \overline{10}$ ] and [001] remains unchanged with $\bar{\theta}$.

It is known that below $\theta=0.7 \mathrm{ML}$. CO adsorbs on both short-bridge and top sites along the $\mathrm{Ni}$ atomic rows with a coverage independent occupation ratio. 4.5

The separation between adsorbed $C O$ molecules is at least $3.74 A$ in the [1 1 0] direction. Above this coverage the need to accommodate more $\mathrm{CO}$ molecules on the surface pushes more molecules to either top cr short-bridge sites ${ }^{4.6 .7}$ and the close packing causes such $\mathrm{CO}$ molecules to tilt altematively towards [001] and $[00 \overline{1}]$ with a tilt angle of $19^{\circ}$ with respect to the surtace normal. ${ }^{8.9 .10}$ The electron orbital overlap of the neighboring $\mathrm{CO}$ molecules along $[1 \overline{1} 0]$ is now appreciable considering that the diameters of $\mathrm{Ni}$ atoms and adsorbed $\mathrm{CO}$ molecules are $2.49 \AA$ and $2.80 \AA$, respectively. This leads to a short range $C O$ CO repulsive interaction which is significantly relieved if one of the molecules would move to a neighboring saddle point on a diffusion pathway. Thus, the diffusion energy barriers are effectively reduced. The above picture qualitatively

explains the decrease of $E_{\text {diff }}$ with increasing $\bar{\theta}$ above $0.7 \mathrm{ML}$ and indicates that it is the short-range CO-CO interaction responsible icr the observed coverage dependence.

For comparison, the desorption energy $E_{D}$ of $C O N i(110)$ measured earitier by Feigerle et al ${ }^{11}$ is reproduced in Fig. 2(a). The resemblance of $E_{0}$ to $E_{\text {dif }}$ as a function of coverage funther suggests that the leng-range CO.CO interaction has negligible influence on the potential variation around the adsorption sites.

We have also investigated the impurity effect on surface diffusion. Figure 3

presents the effect of S impurity on CO diffusion along [1 $\overline{1} 0]$ for $\bar{\theta}-1.0$. In this experiment, $\mathrm{S}$ was deposited on $\mathrm{Ni}(110)$ by exposing the surface with a proper amount of $\mathrm{H}_{2} \mathrm{~S}$. It is seen that even with -.01 to $.02 \mathrm{ML} \mathrm{S}$, the diffusion coefficient $D$ for $C O$ diffusion is already appreciably different from that of a clean surface. The activation energy $E_{\text {dif }}$ monotonically increases from its clean surface value of 
$2.1 \mathrm{kcal} / \mathrm{mol}$ to a saturation value of $-7 \mathrm{kcal} / \mathrm{mol}$ as the $S$ coverage increases to $0.05 \mathrm{ML}$. above which $D$ is further reduced through change in $D_{0}$. In the low temperature region $(-160 \mathrm{~K}), \mathrm{CO}$ ditfusion on $\mathrm{Ni}(110)$ with $-0.05 \mathrm{ML}$ if $S$ impunties is already 2 orders of magnitude slower than on the clean surface. The existing theory cannot explain such a dramatic crange in the $\mathrm{CO}$ diffusion coefficient due to impurities, including the saturation effect, with any realistic S-CO interactions. ${ }^{12}$ It is possible that such adsorbed $S$ atom .juld induce a local surface reconstruction of $\mathrm{Ni}(110) .^{13}$ resulting in a change of local potential barrier for diffusion and hence an increase in the diffusion activaticn energy. Another possible mechanism is that $S$ adsorbates may micrate to the step sites. strongly enhancing the energy bamers at the steps which then dominates the $\mathrm{CO}$ surface diffusion. The effect of surface point defects , created by $\mathrm{Ar}^{+}$sputtering, on $\mathrm{CO}$ cittusion on $\mathrm{Ni}(110)$ has also been studied. The data in (f) and $(g)$ of Fig. 3 were taken on Ni(110) surfaces with different defect densities

for an average co coverage of $\bar{\theta}-1.0$. In (f) the surface after 30 minutes of $\mathrm{Ar}^{+}$sputtering (at $10^{-4}$ tor and $500 \mathrm{~V}$ ) was flash-annealed at $1120 \mathrm{~K}$ for -1

minute. In (g) the surface atter $\mathrm{Ar}^{+}$ sputteri ?g was first annealed at $1120 \mathrm{~K}$ for 10 min. After it was cooled down to

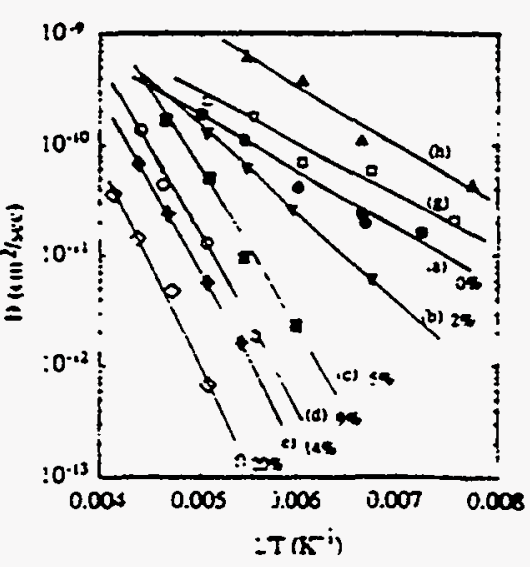

Figure 3: CO Dittusson coefficient at tult coverage $\bar{\theta}-1.0$ along $[\overline{1} \overline{1}]$ of various Ni(1 10) surtaces as a unction of reciprocal temperaturo: (a) nomally prepared clean surteco: (b) - (I). surtaces wath S cosessorbate concentrations of $2 \%$ $5 \%$. 9\%. 14\%. (f) 20\%. rospoctivery:

(g) surface fiastrameated atter $\mathrm{A}^{+}$ spettered. (h) surtac normathy prepared followed by $5 \mathrm{~min} \mathrm{Ar}^{+}$spemering.

room te:mperature, it was $\mathrm{Ar}^{+}$sputtered for $5 \mathrm{~min}$. These two cases are compared to the normally prepared surface (a), which was annealed at $1120 \mathrm{~K}$ for 10

minutes after $\mathrm{Ar}^{+}$sputtering. CO diffusions in cases $(f)$ and $(g)$ are significantly faster, but $E_{\text {diff }}$ remains unchanged.

It is clear that the defect density must increase from (a) to (f) to (g). Our

experi nemal results therefore show unambiguously that $\mathrm{CO}$ diffuses along [1 $\overline{1} 0$ ] on $\mathrm{Ni}(110)$ faster if the defect density is higher. The change comes via the preexponential factor $D_{0}$. Instead of blocking sites in the diffusion pathways, the defects must have increased the apparent jump length in the diffusion process.

In summary, we have shown that linear optical diffraction off an adsorbate grating is an effective and versatile technique for surface diftusion studies. We 
have used it to probe anisotropic CO ditfusion on Ni(110). The coverage dependence of the diffusion has also been measured and proven to be dominated by short-range $\mathrm{CO}-\mathrm{CO}$ interaction. The sulfur impurities on $\mathrm{Ni}(110)$ effectively impede $\mathrm{CO}$ diffusion on $\mathrm{Ni}(110)$ with a significant increase in the diffusion energy barrier. Defects on the surface, on the other hand, speed up the diftusion mainly through an increase in the preexponential factor.

\section{Acknowledgment}

This work was supported by the Director, Office of Energy Research, Office of Basic Energy Sciences, Materials Sciences Division of the U.S. Department of Energy under Contract No. DE-ACO3-76SF00098.

\section{Roferences}

${ }^{1}$ For a recent review, see R. Gomer, Rep. Prog. Phys. 53, 917(1990).

2 Xu-dong Xiao, X.D. Zhu, W. Daum and Y.R. Shen, Phys. Rev. Lett. 66, 2352(1991); Phys. Rev. B 46, 9732(1992).

${ }^{3}$ Xu-dong Xiao, Yuanlin Xie and Y. R. Shen, Surt. Sci. 271, 295(1992).

${ }^{4}$ R. J. Behm, G. Entl and V. Penka, Surf. Sci. 160, 387(1985); S.Haq, J.G.Love

- and D.AKing, Surt. Sci. 275, 170(1992).

5 J. Bauhofer, M. Hock, and J. Kuppers, Surf. Sci. 191,395(1987).

${ }^{6}$ D. J. Hannaman and M.A.Passler, Surf. Sci. 203, 449(1988).

7 B. Voigtlander, D. Bruchmann, S. Lehwald and H. Ibach, Surt. Sci. 225, 151(1990).

${ }^{8}$ W. Riedl and D. Menzel, Surface Sci. 163, 39(1985).

${ }^{8}$ M. D. Aley, M. J. Yates, Jr., Surface Sci. 165, 447(1986).

${ }^{10}$ D.A.Wesner, F.P.Coenen and H.P.Bonzel, Phys. Rev. Lett. 60 , 1045(1988); Phys. Rev. B 39, 10770(1989).

${ }^{11}$ C.S.Feigerle, S.R.Desai and S.H.Overbury, J.Chem.Phys. 93,787(1990).

12 V. P. Zhdanov, Surt. Sci. 194, 1(1988); Phys. Lett. A 137, 225(1989).

${ }^{13}$ D. R. Warburton, G. Thomton, D. Norman, C. H. Richardson and R. Mograth, Surt. Sci. 189/190, 495(1987); R. Baudoing, E. Blanc, C. Gaubert and Y. Gauthier, Surf. Sci. 128, 22(1983). 